\title{
DAMÃO - CINQUENTA ANOS APÓS (1961-2011) OCUPAÇÃO, LIBERTAÇÃO OU SUBJUGAÇÃO?
}

Victor João da Cruz Fernandes

victor.jdc.fernandes@gmail.com

Resumo:Este artigo faz uma sinopse política, económica e da história recente das ex-colónias portuguesas de Goa, Damão e Diu, que há cinquenta anos (I96I) foram anexadas à União Indiana. Há muitas informações pessoais do autor, que assistiu pessoalmente à invasão de Damão pela Índia naquele ano.

Palavras-chave: Goa; Damão; Diu; Índia; Portugal

Em 2oIr relembra-se o cinquentenário da perda por Portugal de suas colónias indianas. Faremos aqui uma apresentação sucinta deles.

\section{A Política}

O Estado Português da Índia, segundo o censo de I930, tinha apenas 637.846 habitantes, dos quais o censo de I96o revelou uma redução para 625.63I habitantes. Era constituído por três territórios costeiros: Goa ao Sul, Damão no Norte, em Gujarat, e Diu, no Saurashtra. Juntos tinham tinha uma área total de quase 4.000 quilômetros quadrados. As praças do Norte ocupavam uma situação estratégica, ficando mesmo à entrada do Golfo de Cambaia e, assim, controlavam todo o comércio costeiro.

I Presidente da Associação Luso Damanense Indiana, Damão, Índia. 
Esses enclaves portugueses no subcontinente indiano eram um pomo de discórdia entre Portugal e a Índia. Já em I5 de agosto de 1947 a União Indiana ganhou a independência e seu primeiro-ministro, numa sessão final da Conferência Literária Maratha de Goa disse que a União Indiana daria todo o apoio a Goa para conseguir a Libertação. Um pouco mais tarde, António Anastásio Bruto da Costa, em 28 de Maio de 1948, condenou a ideologia do Acto Colonial que, na sua opinião, viria a ter graves consequências àquele território. Obcecado na senda da perdição, Salazar nada fez. Em 1949 o Governo de Nova Delhi faz exigências para a extinção do Padroado Português do Oriente, para poderem designar os bispos de Bombaim, Meliapore, Cochin, Mangalore e Thiruchi, concedidos pelo Vaticano aos portugueses, e solicitando que o limitassem à área de Goa, Damão e Diu. Em 27 de fevereiro de 1950, o Governo da União Indiana propôs, através do seu embaixador e ministro em Lisboa um documento que reinvindicava, finalmente, Goa, Damão e Diu e solicitava ao governo português negociações quanto ao futuro das colónias portuguesas na Índia. O governo salazarista responde em 15 de Julho de 1950 , rejeitando a proposta e alegando que o Estado Português era o mais antigo e não se sentia necessidade de qualquer libertação, asseverando que a questão apresentada "não se podia discutir e muito menos aceitar a solução que se propóe". Contudo fica obrigado a fazer negociações com a Santa Sé em i8 de Julho de 1950, revendo as disposições da Concordata de 23 de Julho de I886 e dos Acordos de I5 de Abril de I928.

Houve tumultos no Instituto Indo-Português em Bombaim em 02 de Setembro de 1950. Em 1953 a Índia procurou desatar novamente as negociações, oferecendo-se a manter os laços culturais, a língua, as leis e os costumes portugueses, sendo aquelas novamente recusadas. Salazar, num discurso proferido em ro de julho de I953, repetia:

"Nós não podemos, quer por plebiscito, quer sem ele, negociar a cessação ou a transferência de uma porção do território nacional e dos seus habitantes. Nenhum 
Governo Português o pode fazer, primeiro devido às exigências da Constituição e, depois, devido aos ditâmes da sua consciência do homem."

Não eram apenas os líderes indianos que cobiçavam remover os últimos vestígios da presença estrangeira da Peninsula Hindustânica. Também no decorrer dos anos, foram criados partidos nacionalistas que afirmavam os seus direitos, sendo de relevo o Partido do Congresso $\mathrm{Na}$ cional, fundado em I946, com tendência esquerdista e chefiado por um mangaloriano de origem goesa chamado Peter Álvares, com o apoio de Dr. Telmo de Mascarenhas. Outro elemento mais activo deste partido era o Sr. António Furtado, editor da "Goa Livre".

Os fundadores da Liga Antifacista de Juventude Goesa desligando-se do Partido do Congresso identificaram-se como Partido Nacionalista do Povo Goês para juntar-se com o Partido Comunista Indiano. Os elementos proeminentes deste partido eram Divakar Kakodkar e George Vaz.

A Frente Unida dos Goeses, de Francisco Mascarenhas e Waman Desai, também fizeram a sua estreia no campo político em I950, ao desligarem-se do Congresso e tendo como seu objectivo criar um Estado Autónomo de Goa dentro da União Indiana, contra a ideia de anexação com o Estado vizinho de Maharashtra e, assim, proteger a sua identidade.

O Azad Gomantak Dal, ou seja, a Associação dos Goeses Livres, de V. N. Lawande, expulso do Partido do Congresso e fundado em 1954, em Belgão, contava com o apoio dos extremistas hindus do Jan Sangh, em que se encontravam afiliados os brâmanes damanenses Bhikhubhai Pandya e Motiram Joshi. Este partido exerceu muitas actividades clandestinas dentro do Estado da Índia e enviava satyagrahis para causar distúrbios civis, em nome dos habitantes do território.

Em 1954 emergiu também o Comité de Acção Goesa, fundado pelo marxista Tristão Bragança de Cunha, que intentava coordenar a actividade de vários grupos empenhados na libertação do Estado da Índia. Também nesse ano, em agosto, emergiu o Conselho de Libertação Goesa, 
presidido por António Soares, que foram activos na luta contra os ingleses e agora voltavam-se contra o regime facista de Portugal, constituindo-se de alguns católicos de Bombaim.

\section{A ECONOMIA}

A economia do Estado da Índia em 1953 representava 0.75 por mil do comércio metropolitano. Da metrópole foram enviados io mil contos de mercadorias e o que foi exportado nem chegou a um milhar. Contrastando com isso, as importações feitas pela União Indiana do Estado da Índia atingiam $20 \%$, enquanto a exportação ía para além dos $40 \%$.

Em junho de 1954 o Congresso Nacional (Estado da Índia) lançou o movimento denominado SATHYAGRAHA, que teóricamente consistia em resistência passiva para derrubar o governo português. Os seus voluntários eram afiliados pelos elementos do Partido do Congresso Nacional Indiano, principalmente. Jan Sangh e Rashtra Sevak Sangh, os separatistas e o Partido Comunista, que advogavam inicialmente a autodeterminação. Porém, na prática, esses elementos atacavam postos isolados e fronteiriços, detonavam bombas, destruindo pontes e ligações consideradas essenciais e causavam distúrbios com explosivos colocados nas praças e nos mercados.

Em I5 de julho de I954, o governador de Damão, Major Garrido Borges, ao viajar para os enclaves de Dadrá e Nagar Haveli com um contingente de militares estacionados em Damão, foi impedido de o fazer pelas autoridades indianas. Introduziu-se nesse dia o bloqueio económico aos territórios, isolando-os do resto da Índia. E logo em i8 de julho de I954, forças militares indianas cobertas pelo movimento dos sathyagrahis cerca Dadrá, um enclave circular circundado pela União Indiana e separado de Nagar Haveli por uns quilómetros e invade também o Praganã de Nagar Haveli. Em 2I de julho o posto é atacado à noite. Tombam dois soldados 
portugueses damanenses, o sub-chefe Aniceto do Rosário, filho do Alferes reformado António do Rosário e o guarda António Fernandes, após uma luta renhida que durou para além de quatro horas de angústias e de incertezas.

O bloqueio aperta ainda mais em 1955, proibindo o comércio, a transferência de fundos e a correspondência postal. Em o8 de agosto de 1955 encerra-se a Legação Portuguesa de Nova Delhi. No Parlamento Indiano o Premier Pandit Jawaharlal Nehru afirmou:

"Nós não estamos dispostos a tolerar a presença dos portugueses na Índia, ainda que os seus residentes queiram que ali estejam."

Essas afirmações e os eventos que desencadearam indicam que nem uma nem outra das partes interessadas preocupavam-se com os interesses dos seus habitantes nem com as consequências do povo que iria sofrer.

Nesse mesmo ano, em 4 de novembro de 1954, o delegado soviético refere o caso do Estado da Índia para uma minuciosa fiscalização do desenvolvimento e civilização do território e, em 30 de novembro de 1954, num discurso proferido na Assembleia Nacional, considerou o Estado da Índia indefensável e até optou ser a melhor oportunidade iniciar negociações com os habitantes para uma autonomia progressiva do Estado da Índia. Portugal foi admitido nas Nações Unidas somente em I5 de Dezembro de 1955 e em 22 de dezembro de 1955 recorre ao Tribunal Internacional de Justiça em Haia. O Governo Indiano considera que o Tribunal é incompetente para o reconhecimento das ocupações forçadas e militares dos territórios, mas essa pretensão é rejeitada.

$\mathrm{Na}$ noite de 18 de setembro o Posto de Dodamarogo foi atacado onde morre o tenente miliciano e filho de pais franceses, nascido em Setúbal, Jeán Marie Filiol de Raymond, que se tinha oferecido em I954 para serviço militar na Índia e aonde retornara em 1957. Na madrugada de 22 
de dezembro de 1955, o Posto de Canacona, situado na fronteira a nordeste de Goa, foi atacado e todos os seus onze guardas foram assasinados. Em I2 de abril de I960 o Tribunal profere o julgamento, reconhecendo a soberania portuguesa sôbre os territórios ocupados e o direito de passagem de Damão para os enclaves, desta maneira:

- Rejeita as objecções que a União Indiana levantara quanto a competência do Tribunal.

- Reconhece a soberania portuguesa en Dadra e Nagar Haveli;

- Reafirma o direito de trânsito de cidadãos de Portugal através do território indiano, e relativo ao exercício dessa soberania, de pessoas privadas, funcionários civis e mercadorias em geral, mas considera que o trânsito de tropas portuguesas através do território indiano seria dependente da autorização do governo da Índia, e não pode ser exercido como um direito. Esta assumida vitória não serve a parte alguma e, pelo contrário, foi a causa da precipitação dos eventos acontecidos, tais como a integração total de Dadrá e Nagar Haveli em ir de agosto de i96r na República da India;

- A garantia da cidadania indiana aos seus habitantes.

Enquanto a União Indiana não apresenta recusa formal em dar cumprimento à situação, mantém-se a situação sem nenhuma alteração, enquanto os territórios de Dadrá e Nagar Haveli são declarados Territórios Autónomos sob a administração central da União Indiana

Em fevereiro de 1961 começaram as insurgências em Moçambique, Angola e Guiné. Em 26 de janeiro de I95 a União Indiana proclama-se república secular socialista. A Defesa Nacional, na sua comunicação interna, informa que o ataque deveria recair entre I2 a 15 de dezembro. $\mathrm{O}$ presidente do Conselho dos Ministros envia uma mensagem para manter politicamente a luta pelo menos por oito dias, muito embora um relatório indiano das suas forças armadas, datada de 8 de dezembro de i96r, indi- 
casse que os planos do ministro da Defesa, Krishna Menon, apontava para uma queda que não deveria exceder cinco dias.

\section{OS PREPARATIVOS}

O dia I7 de dezembro raiou muito calmo e pacífico. O governador de $\mathrm{Da}-$ mão, Major António Pinto da Costa, considerou que a força de uns 200 soldados madeirenses e outros de aproximadamente 250 pessoas da força mista da Polícia, Guarda Fiscal e Rural, com uns 50 recrutas adicionais, tinham recebido um treino fenomenal de batalha e, por isso, estavam preparados para o que desse e houvesse. Ainda que a força que tinha era somente para manter a ordem e a paz, o governador e o tenente Falcão, da Polícia, treinaram o melhor que se pôde. $\mathrm{O}$ que mais preocupava o governador era a força e a concentração indiana na fronteira onde estava acampado mais de um batalhão dos famosos gurkas, homens gerreiros que ainda são retidos no exército inglês, e dois regimentos de sikbs, que também têm a fama de perícia no campo de guerra. E para mais além desses intrépidos guerreiros, dois batalhões de Rajputs também se encontravam adicionados para o ataque que seria iminente. Damão tinha uma fronteira bem extensa com a União Indiana e tinha uma superfície de 72 $\mathrm{km}$ quadrados. Não havia para onde recuar e certos pontos fronteiriços distavam menos de 500 metros; a extensão geográfica dificultava ainda mais a colocação e a defesa, pois, em muitos pontos, o inimigo poderia atacar tanto de frente como de trás e isso somente dificultava mais a defesa do perímetro considerado importante. Damão tinha três tanques anfíbios da classe dos Lagartos, um campo de aviação entre o mar e a fronteira, com o único obstáculo natural da Serra da Cruz, e alguns canhões anti-aéreos. Porém o Comandante da Bateria estava hospitalizado.

Mas com tudo isso, Damão foi o único enclave que lutou renhidamente por trinta e seis horas, preparando-se até uma luta de corpo a 
corpo dentro da cidade, até que o governador subitamente foi atingido no centro da cidade por uma bala inimiga traiçoeira. Ainda assim, não se deu por vencido e continuava a luta, enquanto um grupo de cidadãos, composto pelo Dr. Pirosha Luth, presidente da câmara, os comerciantes Sam Wadia, Nariman, Kawas Kabardar, proprietários e cidadãos como Aurélio de Souza, Kesrichande Motichande e Devjibhai Kanjibhai, homens de destaque e líderes, aproximaram-se dele e rogaram para que se rendesse, pois seria uma destruição total, não só da cidade, mas também da sua população indefesa. O Mercado Municipal de Damão Pequeno estava totalmente destruído pelos ataques aéreos. A Fortaleza de S. Jerónimo, onde eram recolhidos os feridos e que continha uma base da Cruz Vermelha, foi também bombardeada, sendo atingidos o frontispício da Igreja de Nossa Senhora do Mar e os baluartes do Forte. Somente isso é que fez com que o governador removesse o seu lenço branco e, colocando-o no cano da metralhadora do seu guarda-costas, meteu-se no seu jipe, foi ao encontro das forças invasoras e ofereceu a rendição.

O coronel Bhonsule, comandante geral das forças invasoras indianas, em pessoa, aproximou-se do Governador, saudou-o militarmente e apertou-1he as mãos, congratulando-o, não como inimigo no campo de batalha, mas como um militar que sabe apreciar a coragem e o valor dum homem destemido, enfrentando precariamente aquela situação, e louvou o Governador na sua coragem em enfrentar uma força numerosa com um punhado de homens e, ainda por cima, deter o avanço inimigo por trinta e seis horas sem tréguas. Uma lápide ainda comemora este glorioso facto, colocada no local obscuro onde o brioso governador foi ferido.

O aeroporto fora, por duas vezes, recapturado, e houve muitos carros blindados e tanques apoiados por bombardeamentos aéreos que intervieram no ataque de ocupação. 


\section{Cinguenta anos Depois}

Hoje tudo parece diferente. A cidade mesquinha de ontem tornou-se uma enorme cidade cosmopolita. As propriedades cresceram de preço, competindo com a cosmopolita Bombaim. Acresceram indústrias e aumentaram infraestruturas que já não se parecem com a pobre cidade que era dantes. Damão tornou-se a capital das indústrias plásticas da Índia. Mas tudo o que se vê é uma ilusão, pois nada disto pode ser creditado ao governo ou, se pudermos pôr duma outra forma, foi acelerado mais pela inactividade do que pelo suporte dele. O governo militar foi substituido por um governo civil, onde um goês, o Senhor Mascarenhas, chefiou-o por uns tempos até que o mesmo foi substituído pelo quadro dos governantes administrativos da Índia da classe do I.A.S. ou seja, Indian Administrative Service.

Primeiro, a cidade cosmopolita de Bombaim, o centro económico da Índia e sua capital financeira, estava abarrotada de contrabandistas, que necessitavam dum campo mais aberto, acessível e sem qualquer restrição policial. Portanto nada poderia determinar uma melhor escolha que $\mathrm{Da}-$ mão, que distava somente uns duzentos quilómetros e era uma localidade ideal, com uma vasta zona costeira, para as suas actividades, a polícia inactiva e sem qualquer controle, e dotado duma administração remota de Goa e quase inexistente. A posição jurídica também se tornou muito benéfica e, além disso, havia uma confusão das legislações.

Com efeito, o Estatuto de Administração de Goa, Damão e Diu foi promulgado sob a XII revisão da Constitutição da Índia para remover as dificuldades experimentadas na administração. O Estatuto da Cidadania de 1955 foi estendido ao território. Isso veio satisfazer os requisitos dos direitos políticos e não civis; por isso, logo depois foi baixado o Decreto da Cidadania, em 3I de maio de 1962, conferindo cidadania por incorporação e, assim, mudando as palavras Portugal e portuguesa, que ficaram substituídas por India e indiana, respectivamente. Foi no ano de 1986 que houve 
uma mudança radical com o Estatuto $\mathrm{n}^{\mathrm{o}}{ }^{\mathrm{I}} \mathrm{I}$, que começou a vigorar desde $\mathrm{I}^{\mathrm{o}}$ de julho de 1987. Enquanto o Estatuto da Cidadania de 1955 concedia a cidadania mesmo a um filho de estrangeiro nascido na Índia, a legislação subsequente retirou os direitos automáticos de cidadania pelo mero facto do nascimento na Índia e o fez dependente do subsequente registo ou naturalização. Os artigos I8-23 do Código Civil Português tornaram-se, agora, a lei interna, ou seja, a lei municipal de Goa, Damão e Diu que definem direitos civis para aqueles territórios.

Tratando-se de Damão, devido a sua situação geográfica e a sua proximidade de Bombaim, os pescadores aventurosos foram expostos aos elementos antissociais da Índia e, assim, em vez da pesca, esses destemidos pescadores iniciaram actividades de contrabando no Golfo Pérsico e, com a mudança do Governo enriqueceram-se. As suas choupanas converteram-se palácios e autênticos edifícios que as suas riquezas clandestinas puderam financiar. Mais tarde, o governo indiano, ansioso por fazer vigorar os seus projectos sociais, aboliu as propriedades das aldeias, promulgando o Daman Abolition of Proprietorship of Villages Act em I962 e, assim, os agricultores e cultivadores repentinamente tornaram-se senhores de propriedades. Encontrando-se numa posição em que não precisavam trabalhar nas terras, ficaram senhores daquilo em que trabalhavam e, assim, aproveitaram a oportunidade para vender as terras nunca dantes possuídas, tornando-se senhores de dinheiro e empenharam-se em construir hotéis e empresas e no desenvolvimento das propriedades, acelerando o desenvolvimento da terra. Mais tarde, vieram as eleições e candidataram-se. $\mathrm{O}$ eleito, como nunca pertencia ou se afiliava a partidos do resto da Índia, mas usavam da sua cobertura para o seu benefício próprio. Foram as eleições que ainda mais levaram os pseudo-políticos a explorar o povo e a terra sem qualquer afinidade política ou sem qualquer sentido. Era comum que, quando uma greve era decretada para toda a Índia, não se estendesse a Damão, que nunca aderia a qualquer comando central ou pan-indiano. 
A distinção e o privilégio de Goa, Damão e Diu é o de terem tido uma legislação uniforme do Código Civil Português que, por mais de um século, governava igualmente as relações jurídicas dos seus cidadãos sem diferença. As concessões existentes para os mouros e hindus no Código de Usos e Costumes são expressamente salvaguardados nela. O Código, por isso, provou ser uma arma poderosa para criar e emular uma coesão bem nítida e homogénea da sociedade com os cidadãos, vivendo em paz e harmonia, e fortalecer aquela unidade da sociedade - a família - salvaguardando os interesses das crianças e viúvas. Contraditoriamente, até certo ponto o Código Português preencheu eloquentemente os ditames do Preâmbulo desta Constituição Indiana em constituir na Índia Portuguesa uma Hegemonia Secular e assegurar uma justiça social e económica para todos os cidadãos, bem como uma igualdade do "status" e a oportunidade e fraternidade com dignidade individual, inexistente aliás no resto da Índia.

Logo após a ocupação, o primeiro acto do Governo Indiano foi o de cortar os emolumentos que os pessoais da administração portuguesa auferiam, incluindo os do quadro da polícia, pois, comparado com os vencimentos indianos no resto da Índia, diferia por mais de 200-500 rupias e, assim, o povo sofreu uma redução nos seus emolumentos. Isso fez levantar uma campanha de protestos até que o primeiro-ministro indiano Jawaharlal Nehru, na sua primeira visita a Goa logo após a sua ocupação, criticou esse acto dos governantes, dizendo que não se podiam cortar os emolumentos dos habitantes do Estado da India, pois eles tinham uma vida bem organizada e mais ocidental, ao contrário do resto da Índia, onde os povos somente se preocupavam em economizar sem gastar ou circular o dinheiro.

DAmão continua a ser o mais pequeno Território Autónomo que, com os enclaves de Dadrá e Nagar Haveli continuam a ser complexamente administrados pelo Quadro de Administração DAINIc (Administração de Damão e Diu, Dadrá e Nagar Haveli, e as ilhas de Andaman 
e Nicobar) em que o Governo Central envia administradores do quadro do I.A.S. para a sua administração. E apesar de Damão ser o mais insignificante quanto a área da sua superfície, o mesmo continua a ser o mais procurado pelos pessoais desse quadro e ainda há muito suborno para obter uma colocação nesse território.

\section{ConClusão}

Damão está perdendo a sua identidade sistematicamente e duma maneira muito destrutiva. Os estranhos na administração em nada se interessam pela sua cultura. Promovem a cultura do estado vizinho de Guzerate e nada da cultura e tradição damanenses.

Enfrentado a realidade presente, descontentes da situação em que se encontra, o povo na sua maioria esmagadora, alega, para abandonar o território, as suas crenças e o seu passado e emigra para o estrangeiro, onde a situação é mais apropriada para o modo de vida com o que estavam habituados.

Damão hoje continua vítima e violada pelos estranhos e calcada pelos seus próprios filhos para um final muito triste e ruim.

AвSTRACT: This paper displays the present situation of the ancient portuguese territories in India (Goa, Daman and Diu), which were invaded in 196r, containing personal information by its author.

Keywords: Goa; Daman; Diu; India; Portugal 